\title{
Investigating the Dislocation-Driven Micro-mechanical Response Under Non-isothermal Creep Conditions in Single-Crystal Superalloys
}

\author{
C. SCHWALBE, J. CORMIER, C.N. JONES, E. GALINDO-NAVA, and C.M.F. RAE \\ The creep responses of the superalloy CMSX-4 under thermal cycling conditions $\left(900{ }^{\circ} \mathrm{C}\right.$ to \\ $\left.1050^{\circ} \mathrm{C}\right)$ and constant load $\left(\sigma_{0}=200 \mathrm{MPa}\right)$ were analyzed using TEM dislocation analysis and \\ compared to the modeled evolution of key creep parameters. By studying tests interrupted at \\ different stages of creep, it is argued that the thermal cycling creep rate under these conditions \\ depends on the creation of interfacial dislocation networks and their disintegration by the \\ $\gamma^{\prime}$-shear of dissimilar Burgers vector pairs.
}

https://doi.org/10.1007/s11661-018-4764-3

(C) The Author(s) 2018

\section{INTRODUCTION}

SINGLE-CRYSTAL nickel-based superalloys are primarily used as turbine blade materials for aeronautical and power generation applications due to their unique resistance under high-temperature creep conditions. In combination with their preferential casting direction and the absence of grain boundaries, the creep life is enhanced due to a bi-phasic microstructure of harder $\gamma^{\prime}$-precipitates (in an $\mathrm{Ni}_{3} \mathrm{Al} \mathrm{Ll}_{2}$-ordered arrangement) coherently embedded in a softer $\gamma$-matrix (disordered fcc). This microstructure has been shown to exhibit maximum creep resistance at a 70 pct $\gamma^{\prime}$-volume fraction at low temperatures. ${ }^{[1]}$ At higher temperatures, due to the increasing solubility of the $\gamma$-phase with temperature, the $\gamma^{\prime}$-phase gradually dissolves, being absent above $1280{ }^{\circ} \mathrm{C}$ in the case of the alloy CMSX-4®.*

*CMSX-4 is a registered trademark of Cannon-Muskegon Corporation.

Lower precipitate fractions have been shown to decrease the creep resistance of the alloys. ${ }^{[2]}$ This is

C. SCHWALBE, E. GALINDO-NAVA, and C.M.F. RAE are with the Department of Materials Science and Metallurgy, University of Cambridge/Rolls-Royce University Technology Partnership, 27 Charles Babbage Road, Cambridge CB3 OFS, UK. Contact e-mail: cr18@cam.ac.uk J. CORMIER is with the Département Physique et Mécanique des Matériaux, Institut Pprime, CNRS-ENSMAUniversité de Poitiers, UPR CNRS 3346, ISAE-ENSMA-Téléport 2, 1 avenue Clément Ader, BP 40109, F86961, Futuroscope Chasseneuil cedex, France. C.N. JONES is with Rolls-Royce plc, PO Box 31, Derby, DE24 8BJ, UK.

Manuscript submitted March 12, 2018.

Article published online July 10, 2018 particularly relevant when analyzing alloys under in-flight conditions as these experience short spikes of high temperature during the take-off step. The micro-mechanical response under non-isothermal conditions has been shown to reduce the lifetime of an alloy relative to its isothermal creep life. ${ }^{[2,3]}$ By varying the non-isothermal exposure cycles in the temperature range of $1050{ }^{\circ} \mathrm{C}$ to $1150{ }^{\circ} \mathrm{C}$, Giraud et al..$^{[4]}$ concluded that one crucial factor for the lifetime reduction is accredited to the development of rafts. This observation is at odds with the well-established beneficial role of $\gamma^{\prime}$-rafting under isothermal conditions. ${ }^{[5]}$ This paper seeks to clarify the role $\gamma^{\prime}$-rafting plays under non-isothermal creep conditions at the lower temperature range of $900{ }^{\circ} \mathrm{C}$ to $1050{ }^{\circ} \mathrm{C}$. Particular attention will be given to the dislocation mechanisms driving damage accumulation $^{[6]}$ and the role of interfacial dislocation networks ${ }^{[2,7]}$ under cyclic creep conditions. This study is aimed at understanding, quantifying, and ultimately modeling the dislocation response under non-isothermal creep.

\section{EXPERIMENTAL PROCEDURES}

\section{A. Materials}

The experiments were performed using a second-generation Ni-based single-crystal superalloy, CMSX-4® (nominal composition shown in Table I). The sample had previously received a standard heat treatment (stepped solution heat treatment with a peak of $2 \mathrm{~h} /$ $1321^{\circ} \mathrm{C} /$ air quench (AQ), and age cycles of $6 \mathrm{~h} /$ $\left.1140{ }^{\circ} \mathrm{C} / \mathrm{AQ}, 20 \mathrm{~h} / 870^{\circ} \mathrm{C} / \mathrm{AQ}\right)$, resulting in dissolution of the $\gamma / \gamma^{\prime}$ eutectic, a 70 pct volume fraction, and an average $\gamma^{\prime}$ precipitate size of $0.45 \mu \mathrm{m}$. The creep test specimens' crystal orientation exhibited a maximum offset of $8 \mathrm{deg}$ from the [001]-direction. All specimens 
were machined into a number of cylindrical specimens of a shape of $3.7 \mathrm{~mm}$ in diameter and $14 \mathrm{~mm}$ gauge length. Finally, a gauge length surface polish was performed to avoid any premature failure during the thermomechanical creep test.

\section{B. Creep Tests}

The non-isothermal creep tests were performed on a Lever Arm Setra SF 2400 creep rig using a calibrated deadweight, equipped with a radiant furnace controlled by a Eurotherm 2408 controller with extension measured by a Keyence LS7070T optical extensometer (see Figure 1(a)). The temperature was controlled by an S-type thermocouple spot welded to the center of the gauge length. The calibrated offset measured by the thermocouple at peak temperature was $\pm 0.85^{\circ} \mathrm{C}$. The load was held at an initial applied stress of $200 \mathrm{MPa}$, decreasing during the high-temperature exposure by $4 \mathrm{MPa}$.

The non-isothermal creep tests consisted of a continuous four-segment temperature cycle of a variable holding time at the base temperature, a heating segment, a 3-minute hold at high temperature, and cooling to base temperature (see Figure 1(b)). Hence, the three cycle times differed only by the holding time at base temperature, which were 9,18 , and 27 minutes, corresponding to the black, blue, and red lines in Figure 1(b), respectively. The heating and cooling rates were kept constant at $120 \mathrm{~K} / \mathrm{min}$ and the resulting overshoot at the high-temperature hold and base temperature was +3 and $-4 \mathrm{~K}$, respectively. Each cycle type was interrupted at four stages of creep life: just after the first heating cycle, and after heating cycles corresponding to approximately $0.5,1$, and 2 pct plastic strain. The test was stopped each time once the sample had just cooled

Table I. Chemical Composition of the Superalloy CMSX-4 (Weight Percent)

\begin{tabular}{lcccccccccc}
\hline & $\mathrm{Al}$ & $\mathrm{Co}$ & $\mathrm{Cr}$ & $\mathrm{Hf}$ & $\mathrm{Mo}$ & $\mathrm{Ti}$ & $\mathrm{W}$ & $\mathrm{Re}$ & $\mathrm{Ta}$ & $\mathrm{Ni}$ \\
\hline CMSX-4 & 5.7 & 9.7 & 6.4 & 0.1 & 0.6 & 1 & 6.4 & 3 & 6.5 & bal. \\
\hline
\end{tabular}

back down to $900{ }^{\circ} \mathrm{C}$. The final cooling rate was $163 \mathrm{~K} /$ min until $700{ }^{\circ} \mathrm{C}, 112 \mathrm{~K} / \mathrm{min}$ until $500^{\circ} \mathrm{C}$, and $55.5 \mathrm{~K} /$ min thereafter. The load was removed once the sample had cooled down to $500{ }^{\circ} \mathrm{C}$.

\section{Microscopy}

The SEM images were taken using a Zeiss Gemini 300 microscope, imaging at $5 \mathrm{kV}$ using the In-Lens detector. The deformation accumulation was investigated with a JEOL 200CX TEM at $200 \mathrm{kV}$ using a double-tilt holder. Blank discs were cut with a thickness of $200 \mu \mathrm{m}$ with approximately $\langle 001\rangle$ and $\langle 111\rangle$ surface normal. From these blanks discs, foils were made by twin-jet electro-polishing in a solution of 6 pct perchloric acid in methanol cooled to $-5{ }^{\circ} \mathrm{C}$. In order to improve resolution in comparison to bright-field imaging (BF) weak-beam dark-field (WBDF) micrographs were recorded in regions of interest.

\section{RESULTS}

\section{A. Test Data from Creep Test}

To obtain plastic strain creep curves comparable to isothermal creep tests, only the base temperature strain data were extracted from the measured sample elongation (see Reference 8). The mean elongation per cycle step was then calculated and the dataset fitted to a best fitting polynomial function. The calculated accumulated creep strain over the test time for the 2 pct strained samples is plotted as curves in Figure 2(a) for the three different cycle times: black line corresponding to 9, blue to 18 , and red to 27 minutes at base temperature. The end points for the interrupted tests (to 0.5 and $1 \mathrm{pct}$ plastic strain) are also shown in corresponding color.

Comparison between the three interrupted tests shows good agreement for the 9 minutes at the base temperature condition. The 18 -minute test plotted to 2 pct strain deformed faster than the 0.5 and 1 pct tests. Similarly, for the 27 -minute condition, the 0.5 pct test deformed faster than the 1 and 2 pct tests. Scatter in creep test data has been widely published (e.g., see

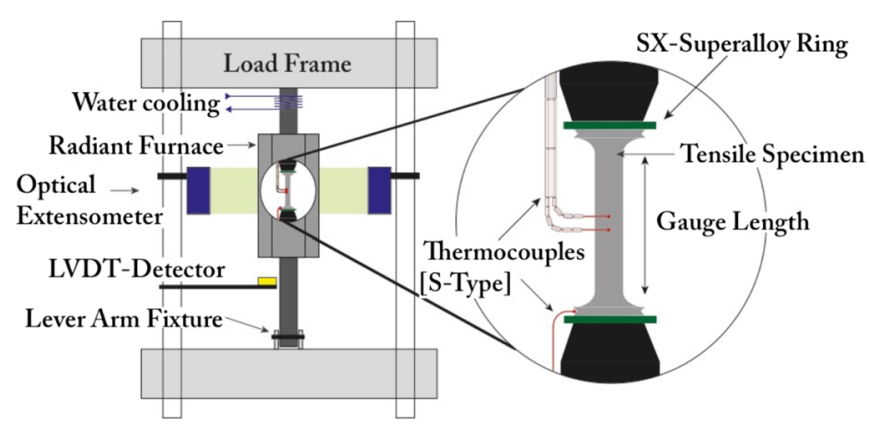

(a)

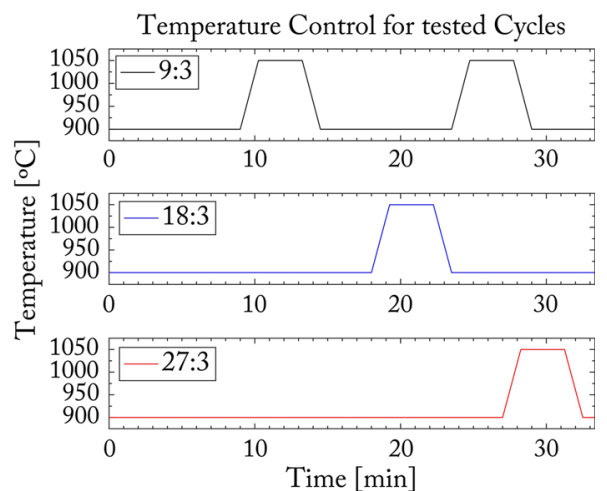

(b)

Fig. 1-(a) Sketch of the used test set-up on the creep frame; (b) non-isothermal temperature control for the three different cycle times $(9: 3,18: 3$, and 27:3 top to bottom) tested. 


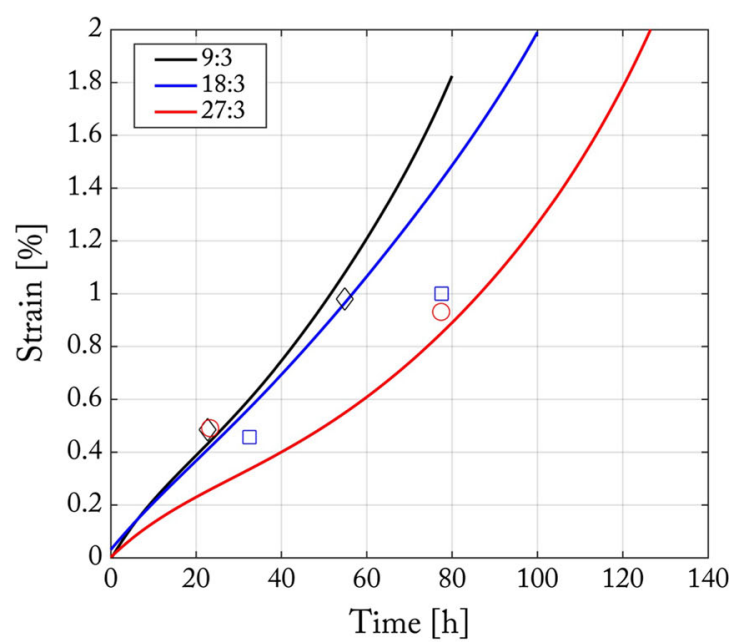

(a)

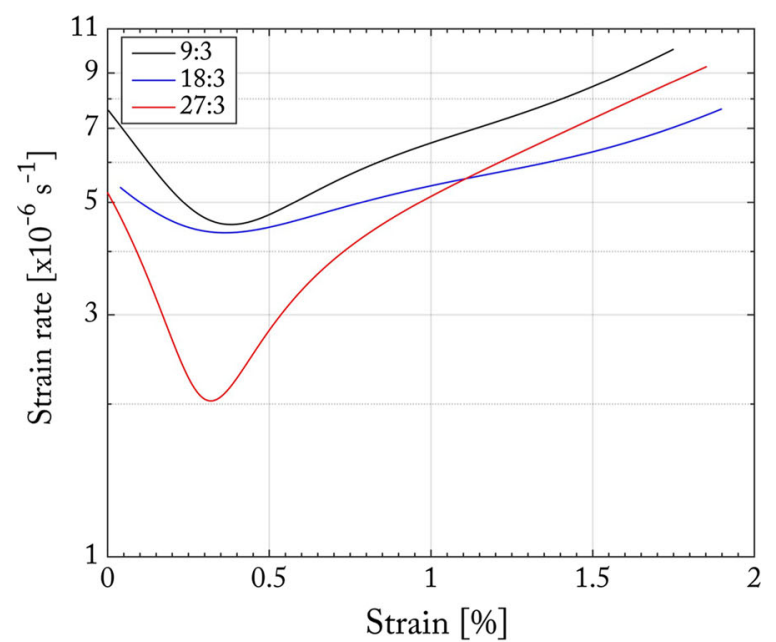

(b)

Fig. 2-(a) Plastic strain accumulated over time for the three non-isothermal test conditions presented in Fig. 1(a): black (9:3), blue (18:3), red (27:3); Creep curves from experiments taken to $\sim 2$ pct strain and end points taken from the interrupted tests in corresponding color to the curves $(b)$ logarithm of strain rate over strain derived from Fig. 2(a) (Color figure online).

Table II. Comparison of the Three Test Cycle Condition Times at Peak $\left(1050{ }^{\circ} \mathrm{C}\right)$, Base $\left(900{ }^{\circ} \mathrm{C}\right)$, and Total Number of $\mathrm{Cycles}$ up to Each Interrupted Stage (Single Cycle, 0.5, 1, and 2 Pet Accumulated Plastic Strain)

\begin{tabular}{|c|c|c|c|c|c|}
\hline Test Cycle/Plastic Strain & & Single Cycle & $\sim 0.5 \mathrm{Pct}$ & $\sim 1$ Pct & 1.8 Pct \\
\hline \multirow[t]{3}{*}{$9: 3$} & $t_{\text {peak }}[\mathrm{h}]$ & 0.05 & 4.7 & 11.35 & 16.42 \\
\hline & $t_{\text {base }}[\mathrm{h}]$ & 0.15 & 14.1 & 34.05 & 49.26 \\
\hline & $N_{\text {cycles }}$ & 1 & 94 & 227 & 328.40 \\
\hline \multirow[t]{3}{*}{$18: 3$} & $t_{\text {peak }}[\mathrm{h}]$ & 0.05 & 4.15 & 9.9 & 11.89 \\
\hline & $t_{\text {base }}[\mathrm{h}]$ & 0.30 & 24.9 & 59.7 & 71.31 \\
\hline & $N_{\text {cycles }}$ & 1 & 83 & 198 & 237.70 \\
\hline \multirow[t]{3}{*}{$27: 3$} & $t_{\text {peak }}[\mathrm{h}$ & 0.05 & 2.15 & 7.15 & 11.13 \\
\hline & $t_{\text {base }}[\mathrm{h}]$ & 0.45 & 19.35 & 64.35 & 100.13 \\
\hline & $N_{\text {cycles }}$ & 1 & 43 & 143 & 222.50 \\
\hline
\end{tabular}

Figure 2 in Reference 9) and is attributed to small offsets in single-crystal orientation as well as chemical composition. While all test pieces were within the tolerances presented, minor variations in composition throughout the cast bar were enhanced by the small sample dimensions. Furthermore, the tolerances of the machining process resulted in a $2 \mathrm{deg}$ offset variation to the [001].

Figure 2(b) shows the derived creep strain rate $\left(\mathrm{s}^{-1}\right)$ over the accumulated strain from the curves in Figure 2(a). The overall strain rate decreases for longer cycle times.

Further, Figure 2(b) indicates that the minimum strain rate across the non-isothermal tests is reached around 0.35 pct strain. This minimum strain rate is in the same order of magnitude as isothermal test data of CMSX-4 at $1050{ }^{\circ} \mathrm{C}$ and $170 \mathrm{MPa},{ }^{[9]}$ if extrapolated to the load applied in this study and more than four orders of magnitude faster compared to $900{ }^{\circ} \mathrm{C}$. ${ }^{[9]}$

Table II illustrates the relationship between the different cycle types and the times spent at base and peak temperature condition, as well as the total number of cycles for each test. The table highlights that in order to accumulate the same amount of plastic strain, the three tested conditions have undergone a very different number of cycles and thus spent different lengths of time at the maximum test temperature. The 9:3 test condition underwent the most cycles and thus spent the most time at peak temperature (just above $1 / 5$ th of the total test time until 1.8 pet plastic strain). In comparison, the test with the slowest strain rate and longest creep life, 27:3 spent below $1 / 10$ th of lifetime at peak temperature. As a result, the 9:3 test has the lowest deformation per cycle but the highest strain rate overall, while the 27:3 condition accumulates the most strain per cycle. Similar relationships with varying time at base temperature condition have been published by Raffaitin et al. ${ }^{[10]}$ and Giraud et al. ${ }^{[4]}$ for thermal cycles to $1150{ }^{\circ} \mathrm{C}$.

\section{B. Evolution of the Microstructure}

As the test pieces were machined from the same cast bar, a similar microstructure was the starting point of each test condition. Following a single heating cycle, no microscopically visible alteration to the cuboidal microstructure had occurred (see Figure 3).

With 0.5 pct plastic strain accumulated in the test pieces, the effects of $\gamma^{\prime}$-rafting and deformation became 


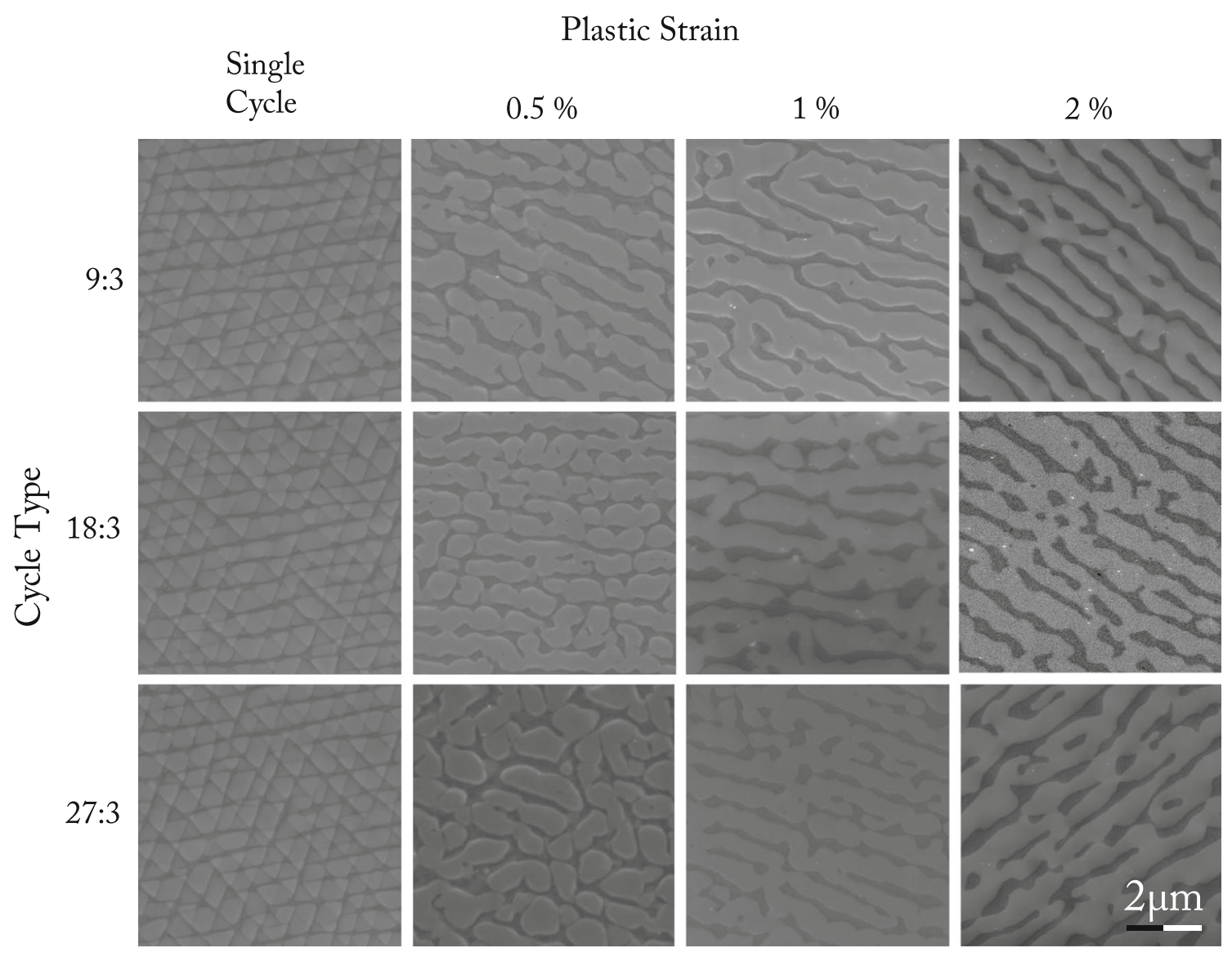

Fig. 3-SEM (In-Lens) micrographs (5 kV). TEM foils cut on the 111-planes. Figures are arranged by cycle type (9:3, 18:3, and 27:3 left to right) and strain accumulated (single cycle, $0.5,1$, and 2 pct plastic strain top to bottom). Dark phases correspond to the $\gamma$-matrix and bright ones to $\gamma^{\prime}$-precipitates.

Table III. Special Connectivity Number for the Dendritic (DC) and Inter-Dendritic (IR) Regions of the 2 Pct Strained Samples for the Three Conditions Tested

\begin{tabular}{llcc}
\hline Test Condition & Region & $1 \% N_{\mathrm{A}}\left(\gamma^{\prime}\right)\left[\mu \mathrm{m}^{-2}\right]$ & $2 \% N_{A}\left(\gamma^{\prime}\right)\left[\mu \mathrm{m}^{-2}\right]$ \\
\hline $9: 3$ & DC & -0.163 & -0.485 \\
$18: 3$ & IR & -0.255 & -0.460 \\
& DC & -0.085 & -0.154 \\
$27: 3$ & IR & -0.154 & -0.236 \\
& DC & -0.116 & -0.505 \\
& IR & -0.113 & -0.582 \\
\hline
\end{tabular}

visible across all three conditions (see Figure 3). However, the progression of rafting is different between the test conditions. Fully established rafts can be seen for the condition 9:3 only, while condition 18:3 is not fully rafted and the condition 27:3 even less so.

This means that the creep minimum displayed in Figure 2(b) does not coincide with the completion of $\gamma^{\prime}$-rafting, as observed for isothermal creep in CMSX-4 ${ }^{\left[{ }^{[9]}\right.}$ This suggests that the creep minimum under these non-isothermal conditions is likely to be caused by other effects. Another striking difference from isothermal tests (see Reference 11) is the disruption to the normal planar rafting process leading to multiple connections between $\gamma^{\prime}$-layers. Evidence of this is that all three conditions exhibit a number of angled side connections, the number increasing with time spent at base condition.

After 1 pct plastic strain, $\gamma^{\prime}$-rafting is completed for all three conditions. The number of out of plane connections have resulted in islands of $\gamma$-matrix indicating the onset of local topological inversion.

The level of topological inversion was quantified using the approach published by Caron et al. ${ }^{[12]}$ by calculating the special connectivity number $N_{\mathrm{A}}\left(\gamma^{\prime}\right)\left[\mu \mathrm{m}^{-2}\right]$ from SEM images of all the three tests interrupted at 1 and 2 pct plastic strain, imaged in the inter-dendritic and dendritic region (see Table III). 
Evidenced by the negative special connectivity numbers, all three test conditions are topologically inverted after 1 pct plastic strain and have progress further in the level of topological inversion at 2 pct plastic strain. Comparing the results between test types, the 27:3 tests exhibit the highest connectivity numbers at both interrupted stages. The connectivity however does not scale with the total test time, as the 18:3 test resulted in the lowest magnitude of connectivity. The connectivity thus also depends on the dissolution and precipitation kinetics which differ between the 9:3 and the longer test conditions (see Section III-C). As discussed in the following section, the 9:3 test is exposed to a continuous metastable phase fraction regime, which results in an enhanced connectivity with precipitated tertiaries compared to the longer tests.

\section{Modeling the Evolution of Key Parameters}

In the investigated temperature/stress regime, the microstructural deformation is generally accepted to be driven by the evolution of a number of key parameters. These are solid-solution hardening, Orowan backstress and effective diffusivity in the $\gamma$-matrix, anti-phase boundary energy in the $\gamma^{\prime}$-phase, phase fractions, and interfacial misfit stresses (see Chapter 2 and 3 in Reference 13). These alloy and temperature-dependent parameters are estimated for the tested creep conditions in order to understand which parameters contribute to the significant increase in deformation speed compared to isothermal conditions.

\section{Parameters estimated assuming equilibrium composition}

With increasing temperature, the solubility of $\gamma^{\prime}$-forming elements in the $\gamma$-phase increases, resulting in a gradual dissolution of $\gamma^{\prime}$-phase fraction. Using the Thermodynamic Software Thermo-Calc ${ }^{* *}$ and the

**Thermo-Calc ${ }^{\circledR}$ and Dictra ${ }^{\circledR}$ are registered trademarks of Thermo-Calc Software AB.

TCNi7 database, the equilibrium element concentration between $800{ }^{\circ} \mathrm{C}$ and $1220{ }^{\circ} \mathrm{C}$ was estimated for the $\gamma$ (Figure 4(a)) and $\gamma^{\prime}$-phase (Figure 4(b)).

These datasets were further used to quantify the temperature dependence of the solid-solution hardening (SSH) resistance in the $\gamma$-matrix. The resistance was estimated by using the approach published by Labusch in Reference 14, while estimating the lattice parameter using the Vegard coefficients published by Caron, ${ }^{[46]}$ that are based on the experimental work by Mishima et $a l^{[15]}$ (see Section VII-A in the Appendix). The resulting temperature dependence is shown in Figure 4(c), indicating a drop of $18 \mathrm{MPa}$ between base and peak temperature during this study.

In the high-temperature and low-stress creep regime, dislocations have to overcome an anti-phase boundary energy (APB) barrier at the interfaces. ${ }^{[16]}$ Using the Thermo-Calc-based approach published by Crudden et $a{ }^{[17]}$ the thermally dependent ordering energy was estimated using the previously estimated alloy compositions at each temperature step in order to estimate the
CMSX-4 Matrix Composition

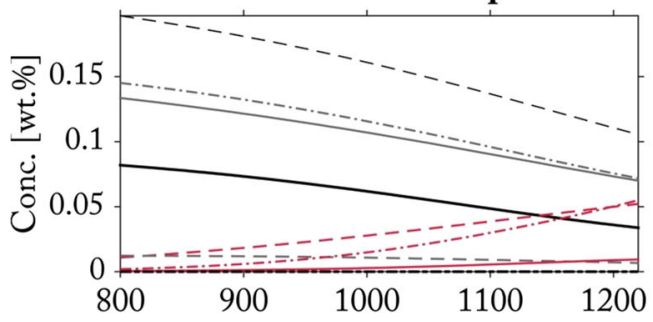

(a)

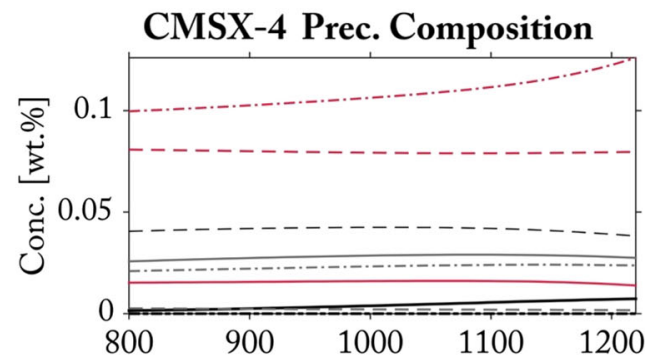

(b)

$$
-\cdot-\mathrm{Cr}--\mathrm{Co}-\mathrm{Re}-\mathrm{W}--\mathrm{Al}--\mathrm{Mo}-\cdot-\mathrm{Ta}-\mathrm{Ti}--\mathrm{Nb}-\cdot-\mathrm{Ru}
$$

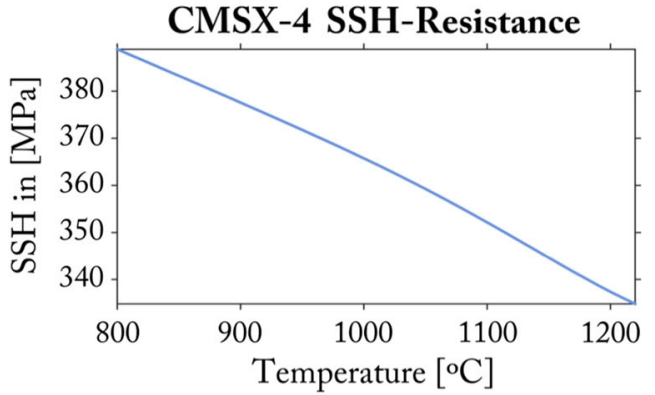

(c)

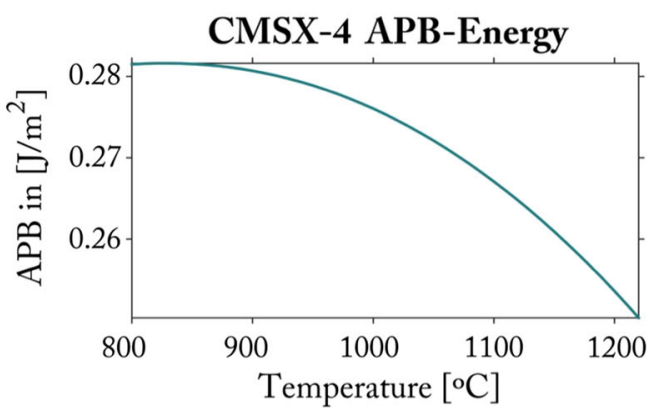

(d)

Fig. 4 - (a) Temperature-dependent element concentration of the $\gamma$-matrix and $(b)$ of the $\gamma$-precipitate phase; $(c)$ estimated solid-solution hardening (SSH) - resistance in $\gamma$-matrix; $(d)$ modeled anti-phase boundary energy at the $\gamma / \gamma^{\prime}$-interface. 
overall temperature dependence of the APB energy. This dependence is presented in Figure 4(d), showing a drop of $8.6 \mathrm{~mJ} / \mathrm{m}^{2}$ between the base and high-temperature values. Assuming an average particle of $450 \mathrm{~nm}$ edge length, this would amount to a drop of $70 \mathrm{MPa}$ in the critical resolved shear stress on heating the sample (see Appendix Section VII-B).

The calculated parameters give an estimate of the parameter evolution during the studied thermal cycling. The actual microstructural values are not only dependent on the local element scatter ${ }^{[18,19]}$ but also depend on the diffusion lengths of each alloying element during thermal cycling.

\section{Parameters estimated assuming} metastable compositions

The phase fraction variation does not precisely track the temperature profile due to the different diffusivities of the alloying elements. ${ }^{[20,21]}$ Instead, as seen in-situ using synchrotron X-ray radiation, ${ }^{[2]}$ the $\gamma^{\prime}$-dissolution lags behind the temperature profiles depending on exposed temperature and thermal gradient.

The $\gamma^{\prime}$-dissolution was approximated with an Avrami equation fitted to an experimental dataset analyzed by the authors. Using an experimental dataset of CMSX-4 thermally cycled under constant load and investigated in situ using X-ray synchrotron radiation. ${ }^{[23]}$ The modeled phase fraction evolution for the three test conditions is shown in Figure 5 starting with heating up to the three-minute high-temperature exposure. The line colors correspond to the test cycles displayed in Figure 1(b). Calculations using the Thermo-Calc module Dictra indicate that following a cooling event, the interfacial compositions are effective in a metastable state owing to the different mobilities of the alloy elements. ${ }^{[23]}$

The phase fraction model suggests that the $\gamma^{\prime}$ in the 14.5-minute-long 9:3 cycle is in a metastable state throughout the test. At the end of a cycle, the $\gamma^{\prime}$-phase fraction roughly reaches its original value.

This is in contrast to the phase fraction evolution of the 18:3 and 27:3 cycling condition, which end in a section of 9 and 18 minutes, respectively, where the equilibrium phase fraction is re-established. These sections are assumed to be similar to the isothermal creep conditions, in that the above-simulated equilibrium model parameters are re-established at the base temperature.

The phase fraction data presented above for the 27:3 test condition was used to estimate the channel and precipitate length evolution during a single cycle, shown in Figures 6(a) and (b), respectively. For this simulation, an average-sized unit cell of one cubic $\gamma^{\prime}$-particle of $450 \mathrm{~nm}$ edge length with a $50 \mathrm{~nm} \gamma$-channel length $(h)$ was assumed. The effect of $\gamma^{\prime}$-tertiary precipitation and dissolution on the effective channel lengths upon cooling
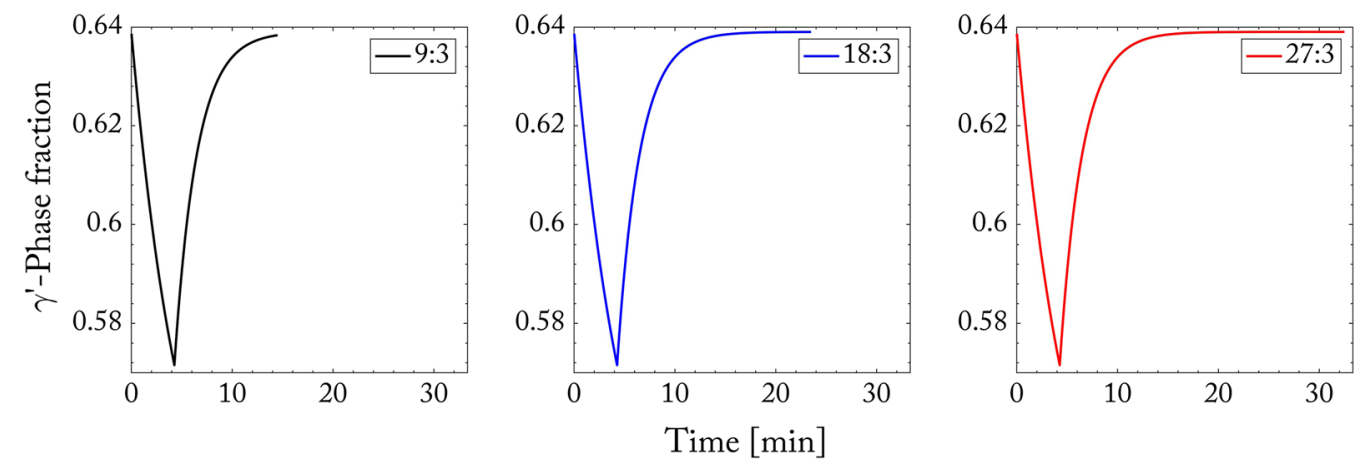

Fig. 5-Modeled $\gamma^{\prime}$-phase fraction evolution for the three test cycles: 9:3, 18:3, and 27:3 (from left to right).

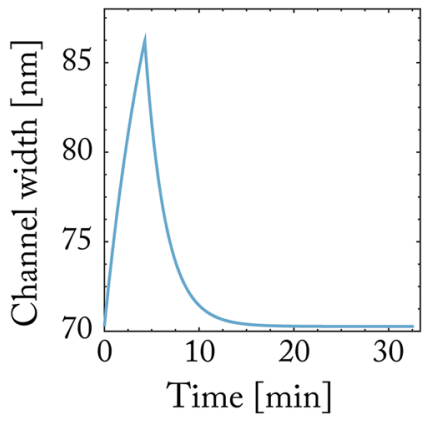

(a)

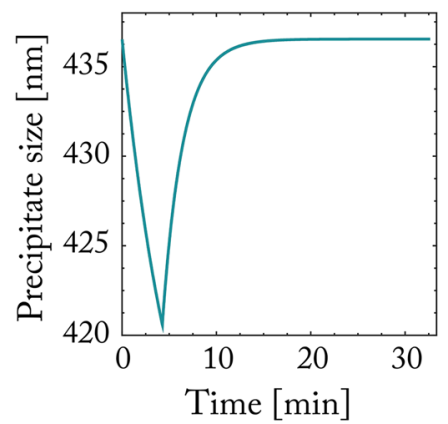

(b)

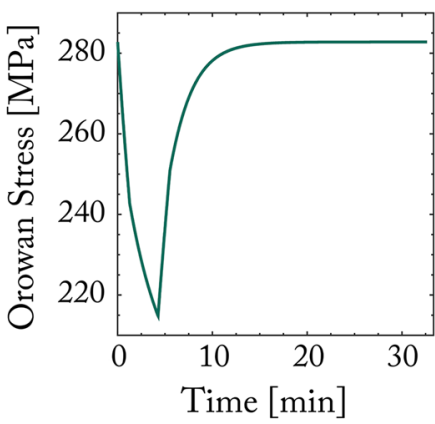

(c)

Fig. 6-(From left to right) modeled evolution for the 27:3 test condition of the $\gamma$-channel width $(a)$, $\gamma^{\prime}$-precipitate length $(b)$ and resulting Orowan backstress in the $\gamma$-channel (c). 
was not considered in this model. The $\gamma^{\prime}$-dissolution in this simulated unit cell is estimated to result in an expansion of the $\gamma$-channels by $16 \mathrm{~nm}$ in one direction (from Figure 6(a)).

Using the $\gamma$-evolution, the Orowan backstress $\left(\tau_{\mathrm{Or}}\right)$ in a dislocation-free channel was calculated using Eq. [1] (adapted from Reference 24). The shear modulus $(G)$ data for the corresponding temperatures were taken from Siebörger et al ${ }^{[25]}$ and the Burgers vector $(b)$ was estimated at $2.5 \AA{ }^{[24]}$

$$
\tau_{\mathrm{Or}}=\frac{\sqrt{2} \cdot G \cdot b}{\sqrt{3} \cdot h} .
$$

The evolution of the Orowan backstress is displayed in Figure 6(c), showing a reduction of $65 \mathrm{MPa}$.

However, the stress field driving the dislocations through the microstructure cannot be directly related to the applied stress alone. The true three-dimensional stress field acting in a given unit cell is largely a function of the interfacial lattice misfit from the coherent $\gamma /$ $\gamma^{\prime}$-interfaces (see References 26 through 28). As the interfacial lattice misfit increases in magnitude with temperature, ${ }^{[29-31]}$ the stress field in the microstructure also increases. The increase in interfacial lattice dislocation density is attributed to the increase in lattice misfit. ${ }^{[32]}$

To estimate the energetic and compositional state of the material at each time step, the calculated $\gamma^{\prime}$-phase fraction (Figure 5) was chosen over the temperature control cycle (Figure 1(b)). As phase composition drives the parameter evolution, the metastable evolution of the remaining creep parameters was calculated by correlating the metastable phase fraction evolution at each time step to the corresponding equilibrium phase fraction estimated using the TCNi7 database in Thermo-Calc $\AA$. This corresponding temperature is termed the effective temperature (see Figure 7(a)) which was used to calculate the metastable evolution of the effective interdiffusivity in the $\gamma$-phase $\left(D_{\text {effm }}\right)$ in Figure $7(\mathrm{~b}) . D_{\text {effm }}$ is given by the harmonic mean of all alloying element diffusivities in Nickel estimated using the TCNi7 database in Thermo-Calc ${ }^{\circledR}$ (see Eq. [24] in Reference 33). Additionally, Figure 7(c) displays the metastable evolution of the $\gamma^{\prime}$-shear stress similarly derived from the equilibrium parameters calculated in the Appendix.

The factors driving the increase in plastic strain as a result of cyclic heating are thus thought to be primarily an increase in misfit stress and hence dislocation density, secondarily a decrease in Orowan backstress and increase in vacancy-assisted dislocation climb due to an increased interdiffusivity in $\gamma$, and thirdly a decreasing resistance to shear of the $\gamma^{\prime}$-phase due to a decrease in APB energy.

\section{DISLOCATION ANALYSIS}

To verify the model and its assumptions and to understand their implications on a microstructural level, a dislocation study was undertaken, analyzing the deformation structures of the three test cycle types after interruption at four stages (single cycle, 0.5, 1 and 2 pct plastic strain).

\section{A. The Single Cycle}

Following the first heating cycle, the dislocation activity is localized to areas of low $\gamma^{\prime}$-volume fraction and high interfacial misfit (dendritic cores) and inter-dendritic boundaries (sources of dislocations) as seen in a similar regime by Jácome et al. ${ }^{[34]}$

Tilting to different imaging conditions and using standard visibility criteria (see References 16 and 27]) revealed two active slip systems (see Figure 8(b)). Most dislocations were observed to have bowed into the $\gamma$-channels, pinned by the $\gamma^{\prime}$-precipitate interfaces (see around marker 1 in Figure 8(a)).

The interfacial dislocations of different Burgers vectors (identified in Figure 8(b) as type $\vec{b}= \pm \frac{a}{2}[101]$ and $\vec{b}= \pm \frac{a}{2}[011]$ ) are further seen to interact, beginning to form interfacial dislocation networks (see southeast of markers 2 in Figure 8(c)). No substantial difference

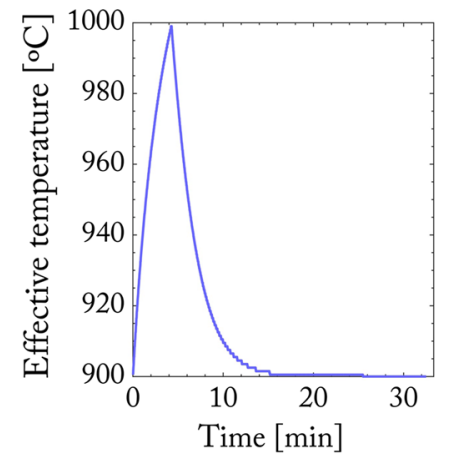

(a)

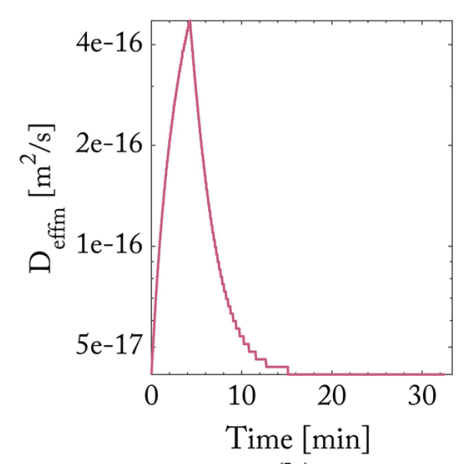

(b)

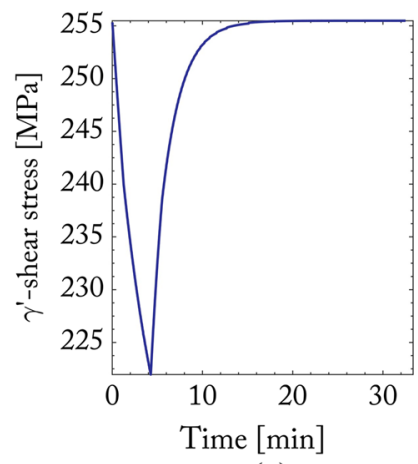

(c)

Fig. 7-(From left to right) modeled evolution for a single 27:3 cycle of the effective temperature (a), effective mean diffusivity $(b)$, and critical $\gamma^{\prime}$-shear stress $(c)$. 

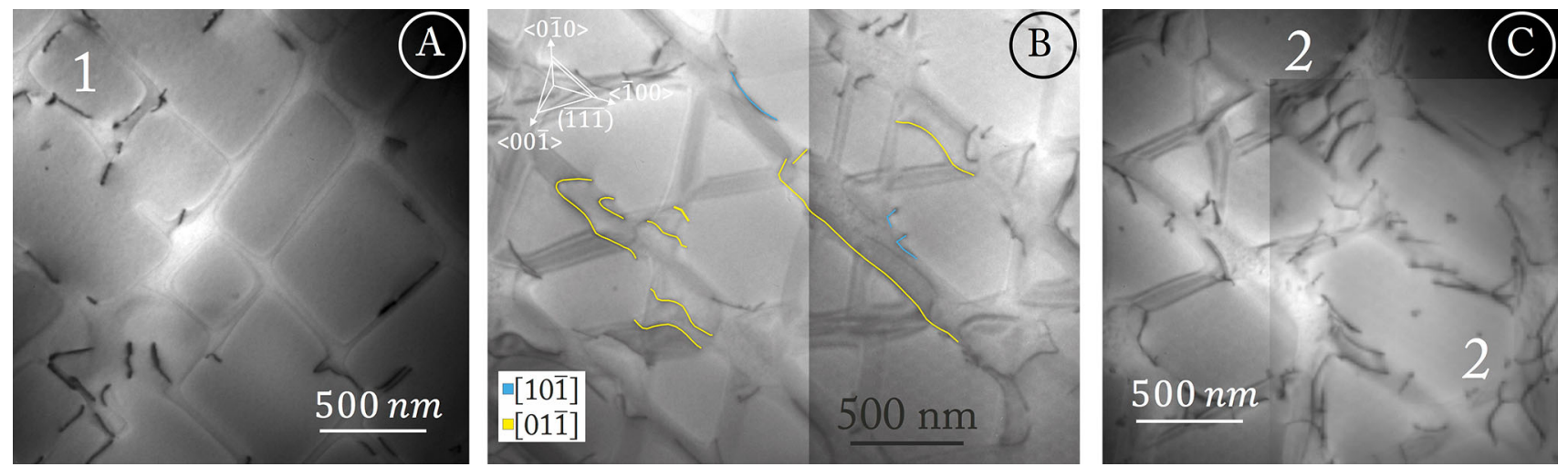

Fig. 8-TEM micrographs imaged after the first heating cycle. (a) BF-image of the 9:3 cycle imaged on the (001) zone axis; $(b)$ BF-image of the 18:3 cycle imaged on the (111) zone axis with $\pm 2 \mathrm{~b} / \mathrm{a}$ vectors and their corresponding dislocations shown; $(c)$ BF-image of the 27:3 cycle imaged on the (111) zone axis.

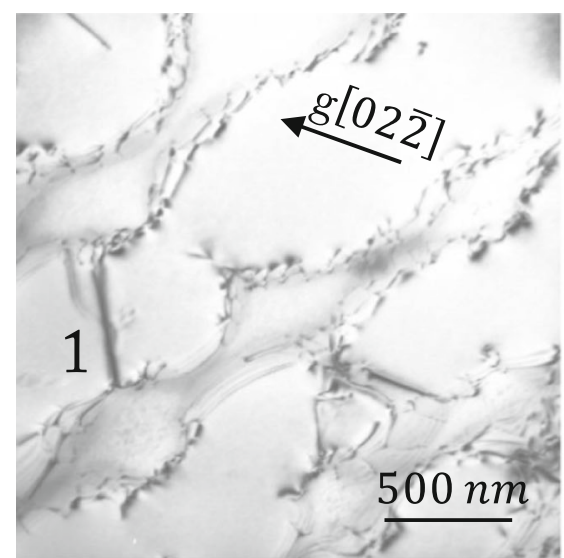

(a)

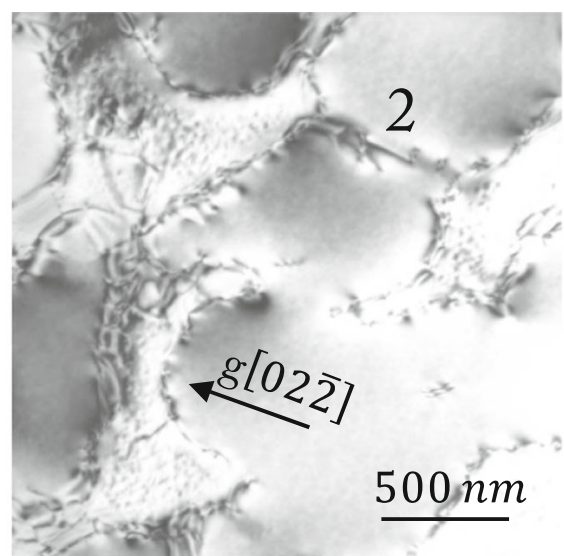

(b)

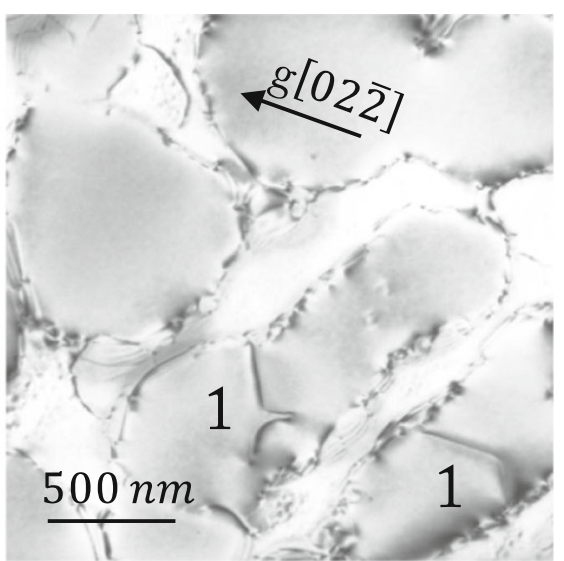

(c)

Fig. 9-BF-TEM micrographs of 27:3 test cycle after 0.5 pct plastic strain imaged on the active (111)-plane in three different regions of the same sample $(a, b, c)$.

could be observed between the three different cycle types following the first heating cycle.

\section{B. Dislocation Structures in the Falling Strain Rate Regime}

With further strain accumulation, continuous interfacial dislocation networks are created. Even in the lowest strain rate test condition (27:3), these networks are established throughout the microstructure after 0.5 pct accumulated strain (see Figure 9).

Closer inspection of the interfacial dislocation networks under different imaging conditions revealed that two different types of networks are present. In Figure 10(a), west and southeast to position 1 networks of single dislocations along the interfaces can be seen. Tilting the specimen to different two-beam conditions and using standard visibility criteria revealed that these were classical interfacial networks of edge character (see Lasalmonie et al. ${ }^{[35]}$ for dislocation reactions and Burgers vectors). In the same Figure, southeast of position 2 a region of the interfacial network can be seen that consists of a paired dislocation of the same Burgers vector side by side. These dislocation pairs were observed for all test conditions (see Figure 10(a) for the 27:3 and Figure 10(b) for the 9:3 test conditions). Using WBDF, the distance between two such dislocation pairs were estimated from such positions as highlighted with a 1 in Figure 10(b), varying between 8 and $15 \mathrm{~nm}$ in width. This proximity suggests that an APB-fault between the pairs stabilizes the configuration as the network has been absorbed into the precipitate phase. Such paired interfacial dislocation networks of type $\vec{b}=\frac{a}{2}[011], \vec{b}=\frac{a}{2}[101], \vec{b}=\frac{a}{2}[110]$ dislocations have been observed by $\mathrm{Ru}$ et al. ${ }^{[36]}$ following isothermal creep at $1100{ }^{\circ} \mathrm{C}$ and $100 \mathrm{MPa}$. However, the dislocation configuration observed by $\mathrm{Ru}$ et al. ${ }^{[36]}$ was identified as pure screw dislocations.

The 0.5 pct strained samples have been interrupted just past the creep minimum strain rate (see Figure 2(b)) and exhibit established dislocation networks on all interfaces even for the longest base temperature cycle condition (see Figures 9 and 10(a)).

In addition to this, a mode of $\gamma^{\prime}$-deformation shown northeast of positions 1 in Figures 9(a) and (c) appears. 

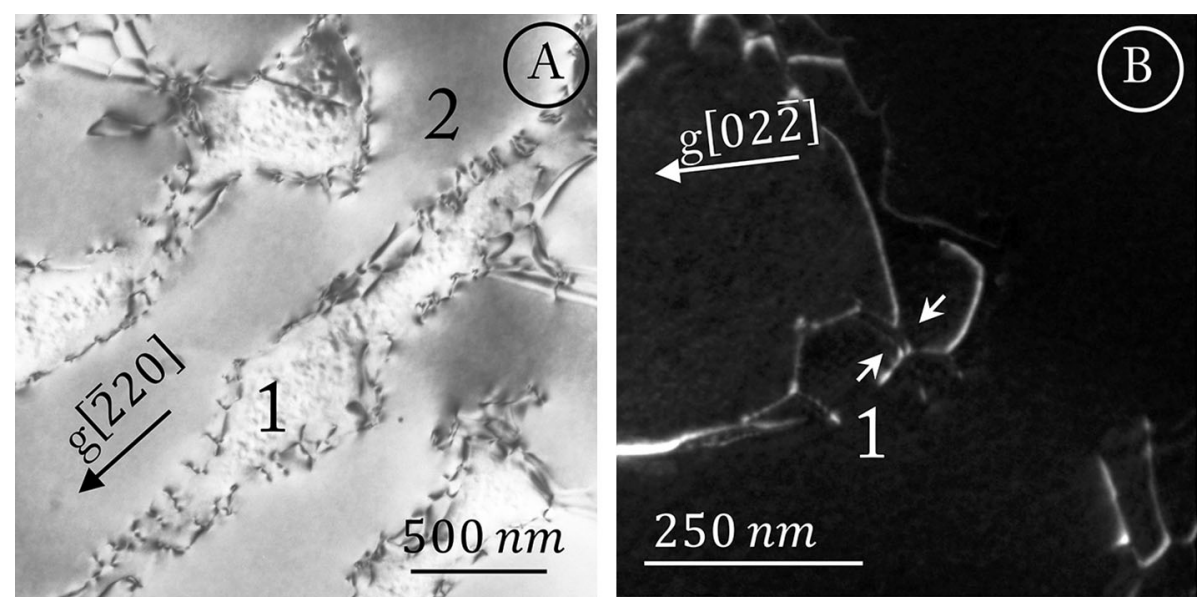

Fig. 10-TEM micrographs of dislocation networks; (a) BF-image of 27:3 test cycle after 0.5 pct plastic strain; (b) WBDF-images of 9:3 test cycle after 1 pct plastic strain; imaged on the active (111)-plane.

Using different imaging conditions (see Figures 12(a) and (b)), these consist of superdislocation pairs of two dissimilar Burgers vectors. These paired dislocations are two different $\mathrm{a} / 2\langle 110\rangle$ dislocations with a net Burgers vector of $a\langle 100\rangle$ which remain closely coupled but with distinct cores. The formation and configuration of these dislocation pairs have been extensively studied by Eggeler et al. ${ }^{[27]}$ in the superalloy CMSX-6 deformed at $1025^{\circ} \mathrm{C}$ and $85 \mathrm{MPa}$ as well as in CMSX-4 at $1020{ }^{\circ} \mathrm{C}$ and $80 \mathrm{MPa}$ by Srinivasan et al. ${ }^{[37]}$ and others. ${ }^{[38-40]}$

The prevalence of different modes of $\gamma^{\prime}$-shearing under isothermal creep at $1020^{\circ} \mathrm{C}$ and $160 \mathrm{MPa}$ for the second-generation superalloy LEK94 after 2 pet strain was studied by Jácome et al.$^{[16]}$ They found that for [001] creep deformation, the principal mode of $\gamma^{\prime}$-deformation was by such $a\langle 100\rangle$ dislocations, with only $3 / 16$ of all superdislocations in the $\gamma^{\prime}$ being of $a\langle 110\rangle$ type.

\section{Regime of Rising Strain Rate}

Past the minimum creep rate, the strain rate increases continuously. Comparing creep strain with the microstructural evolution in Figure 3, this stage seems to be driven by $\gamma^{\prime}$-morphology, i.e., the effects of rafting, coarsening, and local topological inversion.

The process of isothermal $\gamma^{\prime}$-rafting at peak temperature has been published for this alloy by Reed and Matan et al..$^{[9,11]}$ showing that the creep minimum at $1050{ }^{\circ} \mathrm{C}$ and $170 \mathrm{MPa}$ is reached after accumulating 0.4 pet strain.

Looking at Figure 3, the 9:3 test condition has completed rafting under cyclic creep conditions at a comparable accumulated creep strain, whereas the 18:3 and 27:3 conditions complete $\gamma^{\prime}$-rafting later. Accounting for the time each test condition spent at $1050{ }^{\circ} \mathrm{C}$, it becomes clear that the process of rafting during cyclic creep was completed while spending a significantly shorter time in the rafting regime, compared to an isothermal test.
Following the initial incubation time required for the glide-climb formation reaction of Eggeler-type dislocation pairs, these dissimilar Burgers vector pairs can shear the $\gamma^{\prime}$-particles without creating an APB-ribbon (see Eggeler et al. ${ }^{[27]}$ ). As Eggeler et al. pointed out, the formation reaction by climb and glide occurs in the $\gamma$-phase prior to shearing. The dislocation pair then consists of two narrowly spaced dislocation cores that can only be distinguished by looking at their separation on the $\gamma / \gamma^{\prime}$-interface. ${ }^{[27]}$ This can be seen in Figures 11(a) and (b), showing most likely two dislocation pairs (four dislocations in total) having formed in the $\gamma$-matrix east to position 1. As these dislocation pairs were seen from the 0.5 pct strained samples onwards it is suggested that the incubation time for Eggeler-type formation overlaps with the strain necessary to reach the minimum creep rate.

With a net Burgers vector of $a\langle 100\rangle$, these Eggeler-type dislocations are formed from and attached to the $\langle 100\rangle$ and $\langle 010\rangle$ dislocation networks upon shearing through the precipitates (see Figures 11(c) and (d) positions 2 and 3 , respectively). The dislocation motion through the precipitates thus has to overcome the interaction energy between the dislocations and the interfacial networks. Shearing dislocation pairs bound to paired dislocation networks need to remove a single dislocation from each of the different pairs in the 'paired' interfacial network. This requires further energy, such that dislocations not exhibiting the necessary uncoupling energy lie on top of each other (as in the case of 2 pair dislocations at position 3 in Figure 11(d) and at position 2 in Figure 12(c)). When bound to paired networks on both sides of the precipitates, the dislocations exhibit very straight dislocation lines (see position 1 in Figure 9(a), 2 in Figure 11(c), and 3 in Figure 12(c)) indicating that these dislocation lines have sufficient time to adopt their low energy configuration. Moreover, upon breaking away from the interfacial networks, the $\gamma^{\prime}$-shearing dislocations leave behind a distorted network which, until restored and depending on the dislocations Burgers vector, facilitates easier movement through this area. 

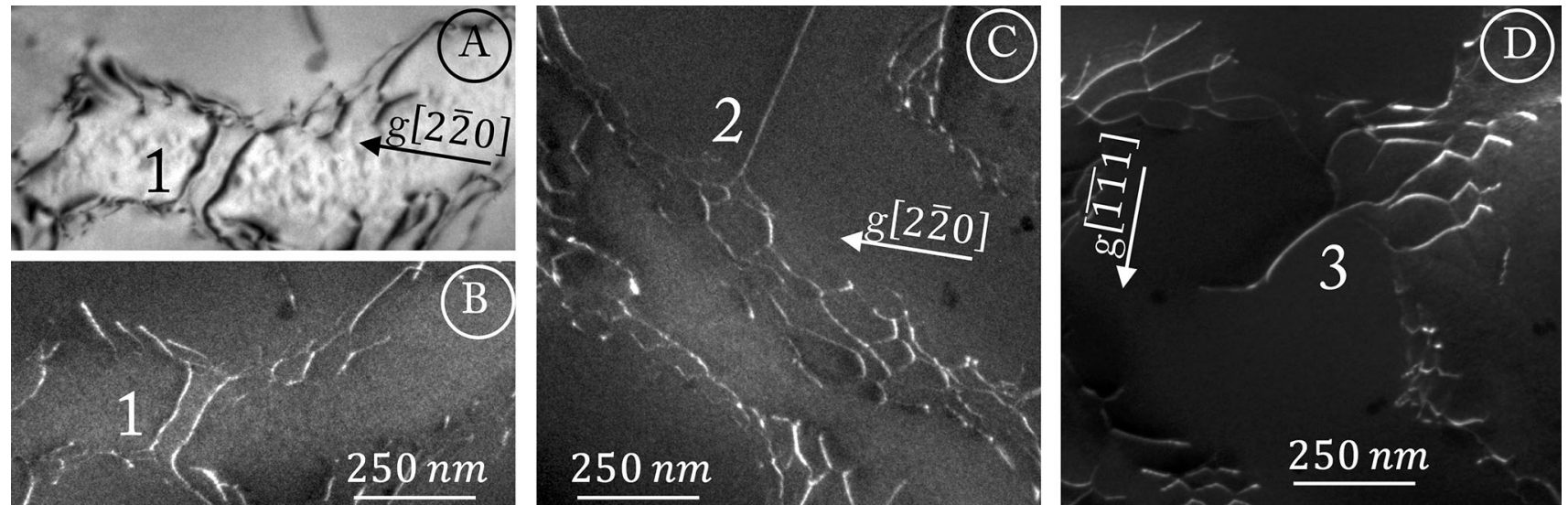

Fig. 11-TEM micrographs of the 9:3 test cycle after 1 pct plastic deformation imaged on the active (111)-plane with (a) BF-image and (b) WBDF-image of the same region as in (a); (c) WBDF-image of a new region with the same tilt and (d) WBDF-image tilted to a new imaging condition as referenced.
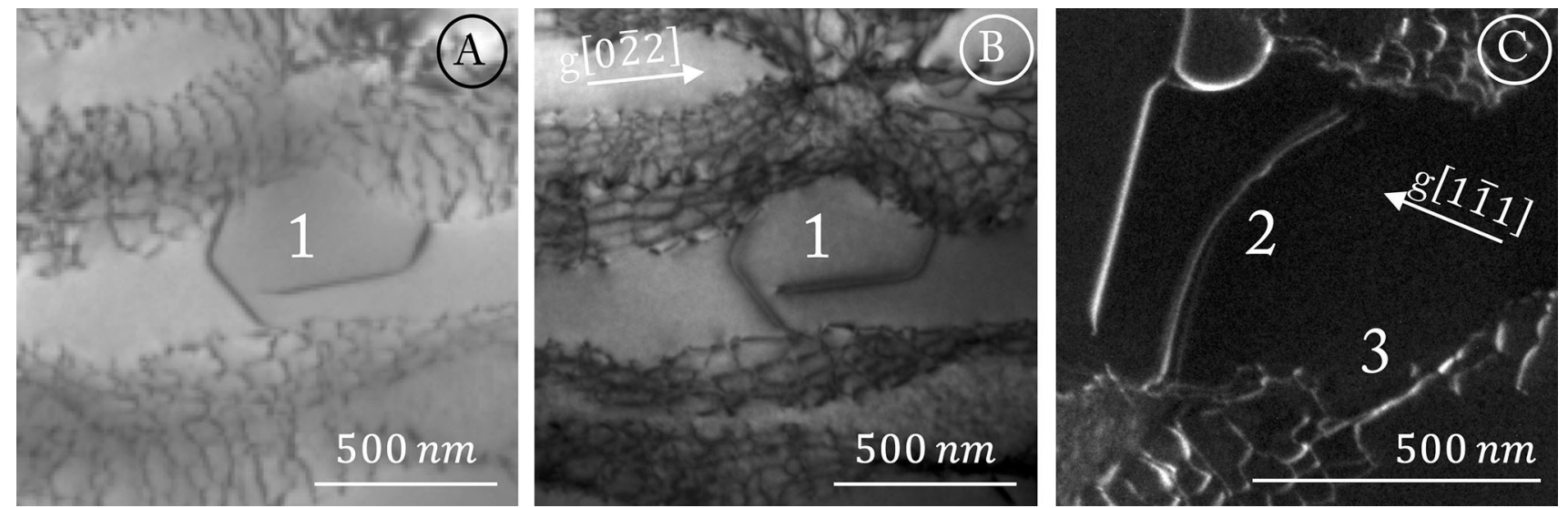

Fig. 12-TEM micrographs of the 9:3 tests imaged on the active (111)-plane after 2 pct accumulated plastic strain. (a) BF-image imaged on the (111)-zone axis; (b) BF-image of the same region as in (a) tilted to the indicated two-beam condition; $(c)$ WBDF-image of a new region.

After 1 pct plastic strain, local topological inversion is thought to further add to the creep acceleration by embedding interfacial dislocation networks into the $\gamma^{\prime}$-phase. An example of this process is shown in Figures 9(b) and 12(c) at positions 2 and 3 respectively. As these absorbed networks are densely packed due to their pairs, the climb distance required to form Eggeler-pairs is small. Thus, these absorbed network dislocations are assumed to be able to pass through $\gamma^{\prime}$ by shear and climb once they have overcome their binding energy to the networks.

Comparing the three test conditions, the mobility of dislocations in the $\gamma^{\prime}$-phase seems to be proportional to the observed strain rate, with the 9:3 condition showing the highest density of dislocation pairs in $\gamma^{\prime}$. This is evidenced by a number of dislocation interactions forming between different Eggeler-pairs within the $\gamma^{\prime}$ for the 9:3 test (see top left of Figure 12(c)). Thus, in line with similar observations by Srinivasan et al., ${ }^{[37]}$ $\gamma^{\prime}$-shearing by glide and climb of interfacial dislocations is proposed as the rate determining deformation factor for the conditions studied.

\section{Topography of the $\gamma / \gamma^{\prime}$-Interface}

The prevalence of $\gamma^{\prime}$-shearing can be attributed to the interfacial network regularity which varies in relation to the cycling rates. Figure 13 displays the interfacial dislocation networks imaged around the [001] zone axis for the three cycling conditions. The variation in brightness over the images, which is particularly pronounced for the 9:3 cycle, is evidence of the change in interface topography within a single raft. This change in topography is then expected to directly affect the arrangement of the superimposed interfacial dislocations. Looking at the network shapes and regularities in Figure 13, it can be concluded that the 9:3 condition results in irregularly spaced double networks (D) around a multifaceted raft. In the case of the 18:3 condition, regions of coherent square networks on a (001)-interface are seen $(\mathrm{O})$ as well as regions of single dislocation networks around a sloped interface (S) and irregular networks around a multifaceted part of the raft (U). In addition, the 27:3 condition displays a region of an elongated hexagonal network of paired dislocations on a (111)-interface $(\mathrm{H})$. 
$9: 3$

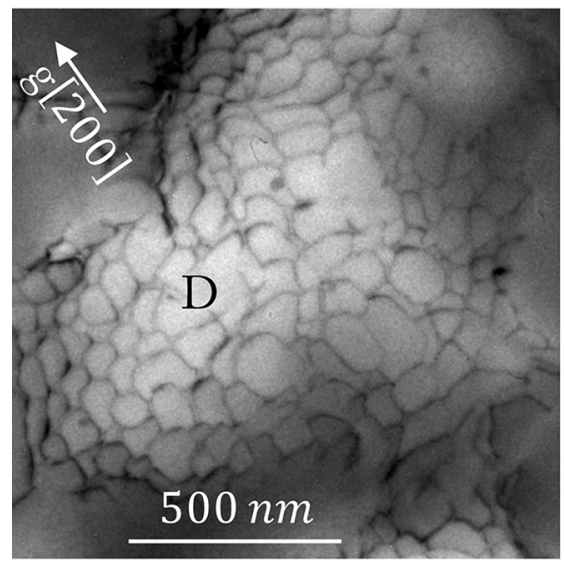

$18: 3$

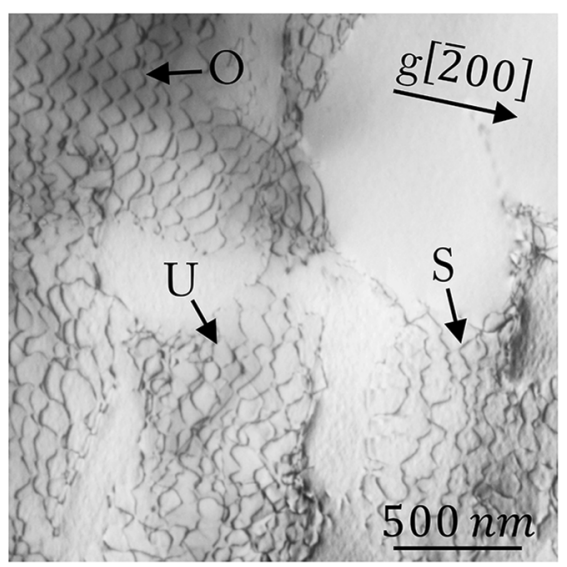

$27: 3$

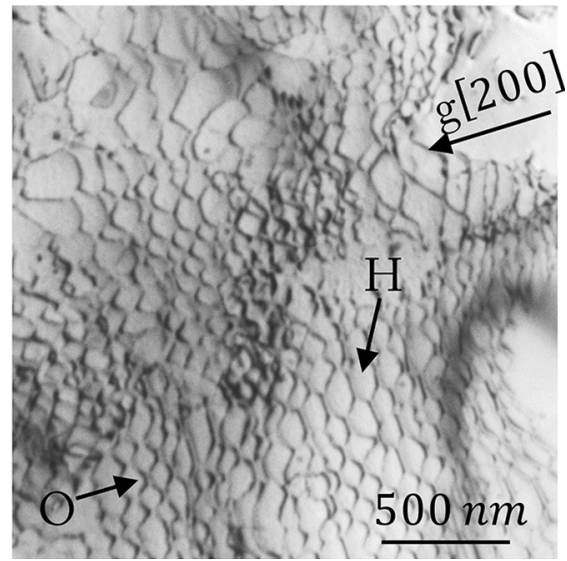

Fig. 13-BF-TEM micrographs of the three test cycles (as labeled) cut on the [001] after $\sim 2$ pct plastic deformation tilted to different two-beam conditions around the zone axis as indicated. See text for further details on the highlighted points.
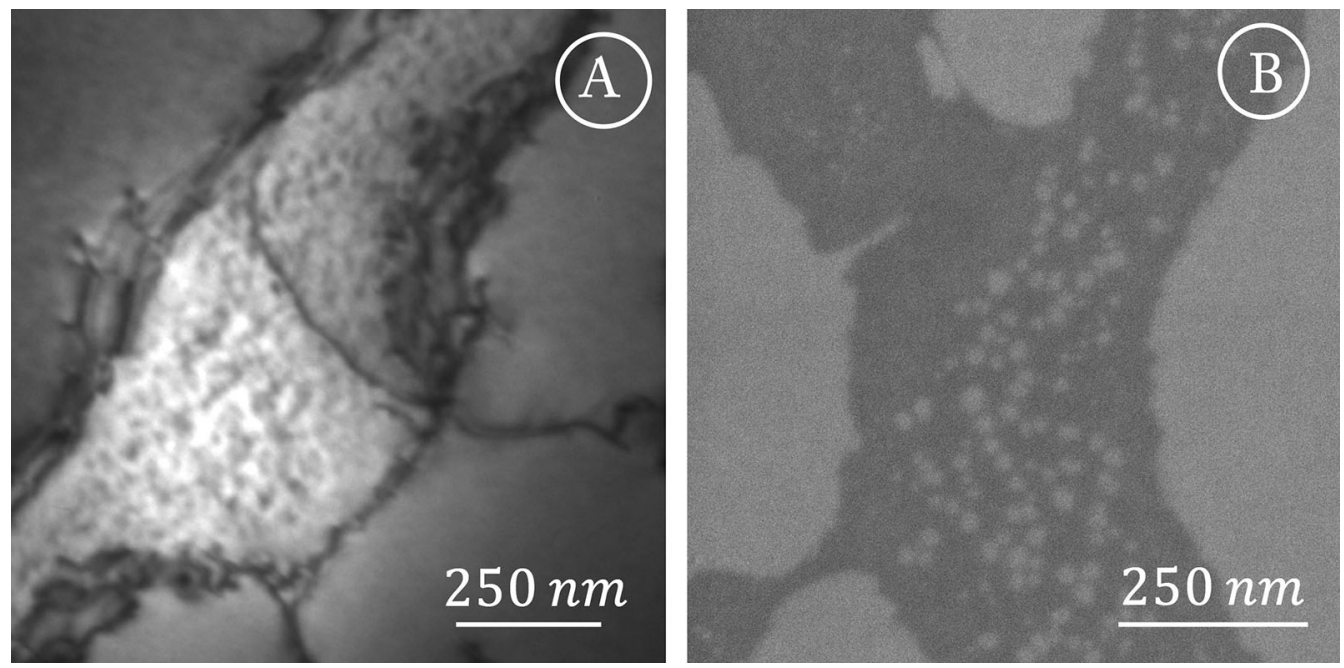

Fig. 14-Micrographs of two different regions from the 27:3 test cycle after 2 pct plastic deformation, imaged on the active (111)-planes' zone axis using two different microscopes: (a) BF-TEM micrograph and (b) SEM micrograph.

\section{E. Role of Tertiaries}

High-temperature cycling has been shown to increase the amount of $\gamma^{\prime}$-tertiaries in the microstructure, which upon precipitation during the cooling segments increase resistance against $\gamma$-glide and push the $\gamma$-dislocations towards the interfaces. ${ }^{[41]}$ As $\gamma^{\prime}$-tertiaries precipitate predominantly in wider $\gamma$-channels (see Figure 14(b)), they rapidly reduce the effective channel width upon cooling, thereby increasing the Orowan resistance.

In this study, the contribution towards creep resistance by $\gamma^{\prime}$-tertiaries could not be investigated, as the electro-polishing preparation step lifted the $\gamma^{\prime}$-tertiaries out of the $\gamma$-matrix (see Figure 14). The distortions on the remaining dislocations gliding in the $\gamma$-matrix (see Figure 14(a)) can thus not be conclusively attributed to $\gamma^{\prime}$-tertiaries or local solid-solution hardening.

\section{DISCUSSION}

As described in Section III-A, the thermal cycling creep conditions studied deform at a significantly faster rate compared to isothermal tests. As the rate of deformation is driven by dislocations, we can assume a higher dislocation activity to be the driving force behind a faster rafting and interfacial network formation process compared to isothermal creep.

The models in Section III-C indicate that the higher dislocation activity during cyclic creep is facilitated in part by a drop in Orowan backstress in $\gamma$, solid-solution hardening resistance in $\gamma$, and anti-phase boundary energy in $\gamma^{\prime}$ during the exposure to $1050{ }^{\circ} \mathrm{C}$. The primary driving forces for the added dislocation activity during thermal cycling are the continuously changing misfit stresses. ${ }^{[22,42]}$ 


\section{A. The Effect of Interfacial Dislocation Networks During Cyclic Creep}

In comparison to isothermal tests, the interfacial dislocation networks are established more rapidly and surround the precipitates after 0.5 pct plastic strain. Thus, the process of network completion precedes the completion of $\gamma^{\prime}$-rafting (see Section III-B) and coincides with the observed minimum creep rate (see Figure 2(b)). The association of the minimum creep rate with the completion of effective interfacial networks protecting against $\gamma^{\prime}$-shear further helps to explain why the creep minimum is reached for all test conditions at roughly the same amount of accumulated creep strain, when the longest cycle $(27: 3)$ is the slowest to form well-developed $\gamma^{\prime}$-rafts (see Figure 3) with the least time spent in the $\gamma^{\prime}$-rafting regime (see Table II).

The networks formed at $\gamma / \gamma^{\prime}$-interfaces are a mixture of single and paired edge dislocation networks, forming as a result of the cyclic peak temperature exposure. To discern the formation mechanism of the paired interfacial networks, further work is required.

To the best knowledge of the authors, dislocation structures originating from non-isothermal cyclic creep have to date only been studied by Viguier and Hantcherli et al. ${ }^{[7,41]}$ Their test series on the superalloy MC2 exposed the material to a peak temperature of $1150{ }^{\circ} \mathrm{C}$ for 30 minutes and cooled the sample down to room temperature in 25 minutes. In other studies of high-temperature (heating to $1050{ }^{\circ} \mathrm{C}$ and more) thermal creep cycling, ${ }^{[2,22,41]}$ the $\gamma^{\prime}$-dissolution was equally large, resulting in a much larger movement of the interface between its peak and base temperature position than in the current study. This greater disruption to the interface is thought to be the reason why paired dislocation networks have not been observed in the cited studies.

The reason why these paired dislocation networks form under the studied test conditions seem to be due to misfit and interface mobility. As no fully established paired dislocation network was observed following a single cycle (see Figures 8), a gradual formation of the networks can be assumed. As reported by Gabb et al., ${ }^{[43]}$ the interfacial network configurations and their Burgers vectors are a response to the misfit and applied stresses, with the network spacing showing an inverse relationship to the misfit. A higher misfit thus results in a denser interfacial dislocation network. In the case of $\mathrm{Ru}$ et al. ${ }^{[36]}$ the paired dislocation network formed during isothermal creep in a 4th generation superalloy with a high misfit. Le Graverend et al. showed that similarly high misfit magnitudes could be achieved during short high-temperature excursions. ${ }^{[22,44]}$ The same study verified in-situ that an increase in misfit magnitude was directly related to an addition in strain accumulation from added dislocation motion. The high-temperature excursions thus require additional interfacial dislocations, while simultaneously decreasing the Orowan glide resistance in the $\gamma$-matrix (see Figure 6(c)) thereby allowing the dislocations to reach their required target quicker.
Due to identical heating cycles, the magnitude of the misfit stresses during the high-temperature exposures is similar across all tests and decreases on cooling (compare with References 22 and 44). The frequency of high-temperature misfit stress regimes, however, is inversely proportional to the cycle time. As a result, the dislocation activity scales accordingly, evidenced in the 9:3 condition having the highest and 27:3 the lowest creep strain (see Figure 2(b)). Consequently, the high-temperature exposures effectively pump dislocations into the microstructure, facilitating a faster interfacial network completion in comparison to isothermal test conditions.

\section{B. The Role of Interfacial Transformation on Cyclic Creep Resistance}

The microstructural evolution during the test (see Section III-B) shows the establishment of non-planar $\gamma^{\prime}$-rafts. The number of side connections between precipitates result in interfacial networks forming along vertical and horizontal interfaces before the completion of $\gamma^{\prime}$-rafting. Further work is required to understand the driving forces resulting in such a disrupted rafting process.

As a result of the continuous precipitate agglomeration (see Figure 3), the bulk $\gamma^{\prime}$-area increases make it easier and quicker for a $\gamma^{\prime}$-pair to shear through the same area. In addition, the interfacial area shrinks requiring fewer interfacial dislocations bound to these interfaces to alleviate the interfacial lattice mismatch. Further, it results in some paired dislocation networks being absorbed by the conglomeration into the $\gamma^{\prime}$ (see Section IV-C). These processes are enhanced during cyclic creep conditions since effective interfacial networks have been completed before $\gamma^{\prime}$-rafting. The process of rafting thus contributes to the creep strain acceleration. This agrees with the observations by Giraud et al. ${ }^{[4]}$ who observed a similarly detrimental effect of rafting on the high-temperature cyclic creep resistance in the $1050{ }^{\circ} \mathrm{C}$ to $1150{ }^{\circ} \mathrm{C}$ regime.

In the studied $900{ }^{\circ} \mathrm{C}$ to $1050{ }^{\circ} \mathrm{C}$ regime, $\gamma^{\prime}$-rafting introduces mobile Eggeler-type dislocation pairs into the $\gamma^{\prime}$ that only have to overcome their network binding energy. The formation of these dissimilar Burgers vector pairs are diffusion activated, and an incubation time at high temperature is required for their formation. ${ }^{[27]}$ Thus, the Eggeler-type pairs are only expected to form during peak temperature segments, once sufficient dislocation density in the $\gamma$-channels is reached to enable a probable encounter. As suggested in Section IV-C, this point is reached around the minimum strain rate. The reactivity of the Eggeler-type dislocations with the paired networks suggests that these dislocation types are a principal contributor to the acceleration of creep in the high-temperature cyclic creep regime (see Section IV-C). As these dislocations do not need to overcome an APB energy to shear, ${ }^{[27]}$ they further highlight the importance of network stability to cyclic creep life. As the topology of the interfacial networks is deformed by the interface plane it surrounds, which 
itself depends on the $\gamma^{\prime}$-phase fraction variation, the cyclic $\gamma^{\prime}$-phase stability is highlighted as a principal parameter driving cyclic creep lifetime.

\section{SUMMARY}

In this study, the cyclic creep response for a tertiary-creep regime dominated base condition, cycling into the $\gamma^{\prime}$-rafting regime was analyzed. It was found that, under these conditions the creep strain rate, the onset of $\gamma^{\prime}$-rafting and the formation of interfacial networks is considerably faster than isothermal testing at base temperature.

The creep life under these cyclic conditions depends on the formation and stability of interfacial dislocation networks rather than $\gamma^{\prime}$-rafting kinetics. The interfacial networks were found to transform from classical single dislocation networks into paired dislocation networks, as a result of becoming embedded in the outer layer of the $\gamma^{\prime}$ due to the repeated exposure to the peak temperature. Highlighting the importance of cyclic phase fraction stability as design criterion for future alloys.

The acceleration of creep strain following the minimum creep rate was attributed to the shearing of the $\gamma^{\prime}$ by dissimilar Burgers vector dislocation pairs.

\section{ACKNOWLEDGMENTS}

The authors would like to thank Institut Pprime at ISAE-ENSMA for providing the mechanical testing facilities, Cannon-Muskegon Corporation (Dr. Jacqui Wahl and Dr. Ken Harris) for providing CMSX-4 specimens. They would also like to thank Rolls-Royce plc and the Engineering and Physical Sciences Research Council (EPSRC) for financial support under the Strategic Partnership, Grant Numbers EP/ $\mathrm{H} 022309 / 1$ and EP/H500375/1. E. Galindo-Nava would like to acknowledge the Royal Academy of Engineering for his research fellowship funding. C. Schwalbe would like to thank Dr. H. T. Pang and M. Wang-Koh for their help and support in TEM microscopy.

\section{OPEN ACCESS}

This article is distributed under the terms of the Creative Commons Attribution 4.0 International License (http://creativecommons.org/licenses/by/4.0/), which permits unrestricted use, distribution, and reproduction in any medium, provided you give appropriate credit to the original author(s) and the source, provide a link to the Creative Commons license, and indicate if changes were made.

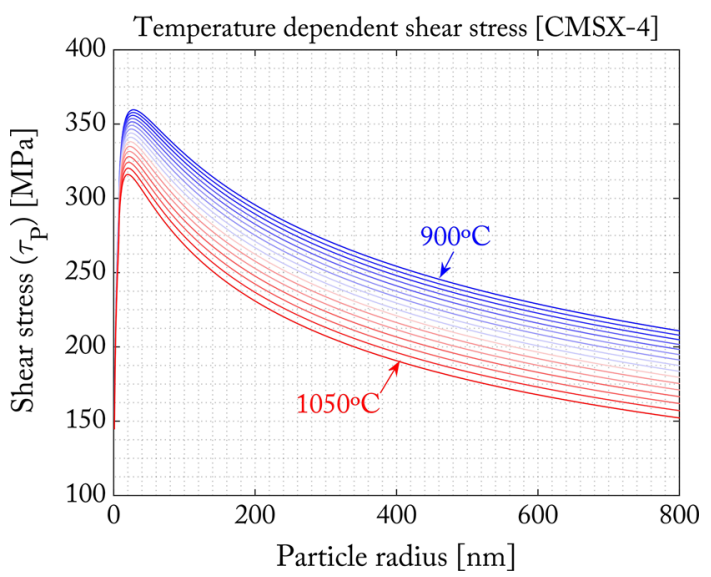

Fig. A1-Precipitate shear stress as a function of the precipitate radius plotted for thermal exposure in the experiments. The upper boundary in blue corresponds to the value at base temperature, the lower red curve plots the high-temperature values.

\section{APPENDIX}

See Figure A1.

\section{SOLID-SOLUTION HARDENING}

The Solid-solution model by Labusch et al. ${ }^{[14]}$ has shown to give a good estimate of this parameter $\left(\tau_{\mathrm{SSH}}\right){ }^{[45]}$ To capture the temperature dependence of this parameter, the change in lattice parameter $(a)$, shear modulus $(G)$, and alloy element concentration $(c)$ was considered at each temperature step. The critical shear strength in the $\gamma$-matrix is estimated by Labusch according to Eq. [A1], where $\varepsilon_{L}$ is the atomic interaction parameter laid out further in Eq. [A2].

$$
\begin{gathered}
\tau_{S S H}=\frac{1}{550} G \varepsilon_{L}^{\frac{4}{3}} c^{\frac{2}{3}} \\
\varepsilon_{L}=\sqrt{\eta^{\prime 2}+\alpha^{2} \delta^{2}} .
\end{gathered}
$$

The parameter $\varepsilon_{L}$ then summates the parelastic interaction $(\delta)$ and the dielastic interaction $(\eta)$ according to Eqs. [A3] and [A4], respectively, with a proportionality factor $(\alpha)$ assessing the interaction between parelastic and dielastic effects, taking a value between 3 and 16 for screw and above 16 for edge dislocations. ${ }^{[45]}$ To account for both types, a value of $\alpha=16$ was used.

$$
\delta=\frac{1}{a} \frac{d a}{d c}
$$

The parelastic interaction describes the change in $\gamma$-lattice constant with a changing composition $(c)$. The 
atomic concentration at each temperature step was estimated using the Thermo-Calc database TCNi7 and then used to estimate the lattice constant with the coefficients published by Caron et al. ${ }^{[46]}$

$$
\begin{gathered}
\eta^{\prime}=\frac{\eta}{1+\frac{1}{2}|\eta|} \\
\eta=\frac{1}{G} \frac{d G}{d c} .
\end{gathered}
$$

The dielastic parameter estimates the change in local bonding energy between the solute atoms in the $\gamma$-matrix resulting from a change in the shear modulus with composition. The shear modulus change was estimated using a linear rule of mixture of the weight fraction compositions estimated with Thermo-Calc and the specific modulus of each element taken from Section 15-1 of Reference 47.

\section{CRITICAL PARTICLE SHEAR STRENGTH ESTIMATION}

The critical shear stress $\left(\tau_{P}\right)$ is dependent on the APB energy, the volume fraction, and precipitate size. The former two parameters were estimated using ThermoCalc database TCNi7 and the approach published by Crudden et al. ${ }^{[17]}$ The precipitate shear strength was then plotted as a function of the precipitate radius in Appendix Figure 15. The model used is a weak and strong coupled unified approach published by GalindoNava et al. in Reference 48. This approach describes the precipitate strength for multimodal particle distributions and was expanded for the case of cuboidal strong coupled precipitates using the Eqs. [A6] and [A7].

$$
\begin{gathered}
h=\frac{L}{f f^{\prime}}-L \\
\lambda=\frac{2 l_{111}}{\sqrt{3}}+\sqrt{2} h,
\end{gathered}
$$

where $h$ is the mean channel, $L$ is the mean precipitate length, and $f \gamma^{\prime}$ is the precipitate equilibrium volume fraction. The shear length on the active slip plane in the precipitate is given by the parameter $\lambda$, which includes the precipitate length on the glide plane $\left(l_{111}\right)$.

\section{REFERENCES}

1. T. Murakumo, T. Kobayashi, Y. Koizumi, and H. Harada: Acta Mater., 2004, vol. 52, pp. 3737-44.

2. J. Cormier, X. Milhet, and J. Mendez: Acta Mater., 2007, vol. 55 , pp. $6250-59$.

3. J. Cormier, X. Milhet, and J. Mendez: mater. Sci. Eng. A, 2008, vols. 483-484, pp. 594-97.

4. r. Giraud, J. Cormier, Z. Hervier, D. Bertheau, K. Harris, J. Wahl, X. Milhet, J. Mendez, and A. Organista: Superalloys, 2012, vol. 2012, pp. 265-74.
5. R.N. Frank and R.N. Nabarro: Metall. Mater. Trans. A, 1996, vol. 27A, pp. 513-30.

6. J.-B. le Graverend, J. Adrien, and J. Cormier: Mater.Sci. Eng. A, 2017, vol. 695, pp. 367-78.

7. M. Hantcherli, F. Pettinari-Sturmel, B. Viguier, J. Douin, and A. Coujou: Scr. Mater., 2012, vol. 66, pp. 143-46.

8. J. Cormier, M. Jouiad, F. Hamon, P. Villechaise, and X. Milhet: Philos. Mag. Lett., 2010, vol. 90, pp. 611-20.

9. R.C. Reed, N. Matan, D.C. Cox, M.A. Rist, and C.M.F. Rae: Acta Mater., 1999, vol. 47, pp. 3367-81.

10. A. Raffaitin, D. Monceau, F. Crabos, and E. Andrieu: Scr. Mater., 2007, vol. 56, pp. 277-80.

11. N. Matan, D.C. Cox, C.M.F. Rae, and R.C. Reed: Acta Mater., 1999, vol. 47, pp. 2031-45.

12. P. Caron, C. Ramusat, F. Diologent: Superalloys, 2008, pp. 159-67.

13. R.C. Reed: The Superalloys, Cambridge University Press, Cambridge, 2006.

14. L.A. Gypen and A. Deruyttere: Scr. Mater., 1981.

15. Y. Mishima, S. Ochiai, N. Hamao, M. Yodogawa, and T. Suzuki: Trans. Jpn. Inst. Metals, 1986, vol. 27, pp. 656-64.

16. L. Agudo Jácome, P. Nörtershäuser, C. Somsen, A. Dlouhy, and G. Eggeler: Acta Mater., 2014, vol. 69, pp. 246-64.

17. D.J. Crudden, A. Mottura, N. Warnken, B. Raeisinia, and R.C. Reed: Acta Mater., 2014, vol. 75, pp. 356-70.

18. M.S.A. Karunaratne, D.C. Cox, P. Carter, and R.C. Reed: Superalloys 2000 (Ninth International Symposium), 2000, pp. 26372.

19. M.S.A. Karunaratne, C.M.F. Rae, and R.C. Reed: Metall. Mater. Trans. A, 2001, vol. 32A, pp. 2409-21.

20. C.E. Campbell, W.J. Boettinger, and U.R. Kattner: Acta Mater., 2002, vol. 50, pp. 775-92.

21. M.S.A. Karunaratne and R.C. Reed: Acta Mater., 2003, vol. 51, pp. $2905-19$.

22. J.-B. le Graverend, A. Jacques, J. Cormier, O. Ferry, T. Schenk, and J. Mendez: Acta Mater., 2015, vol. 84, pp. 65-79.

23. C.W.M. Schwalbe, A. Jacques, E.I. Galindo-Nava, N.C.N. Jones, C.M.F. Rae, and J. Cormier: Communication submitted to MSEA and currently under review.

24. J. Svoboda and P. Lukáš: Acta Mater., 2000, vol. 48, pp. 2519 28.

25. D. Siebörger, H. Knake, and U. Glatzel: Mater. Sci. Eng. A, 2001, vol. 298, pp. 26-33.

26. T.M. Pollock and A.S. Argon: Acta Metall. Mater., 1992, vol. 40, pp. 1-30.

27. G. Eggeler and A. Dlouhy: Acta Mater., 1997, vol. 45, pp. 4251-62.

28. M. Probst-Hein, A. Dlouhy, and G. Eggeler: Acta Mater., 1999, vol. 47, pp. 2497-510.

29. M.V. Nathal, R.A. MacKay, and R.G. Garlick: Mater. Sci. Eng., 1985, vol. 75, pp. 195-205.

30. H.C. Pinto and G. Bruno: J. Synchrotron Radiat., 2003, vol. 10, pp. 148-53.

31. G. Bruno, B. Schönfeld, and G. Kostorz: Zeitschrift Für Metallkunde, 2003, vol. 94, pp. 12-18.

32. J. Zhang, J. Wang, H. Harada, and Y. Koizumi: Acta Mater., 2005 , vol. 53 , pp. 4623-33.

33. Z. Zhu, H. Basoalto, N. Warnken, and R.C. Reed: Acta Mater., 2012, vol. 60, pp. 4888-900.

34. L. Agudo Jácome, P. Nörtershäuser, J.K. Heyer, A. Lahni, J. Frenzel, A. Dlouhy, C. Somsen, and G. Eggeler: Acta Mater., 2013, vol. 61, pp. 2926-43.

35. A. Lasalmonie and J.L. Strudel: Philos. Mag., 1975, vol. 32, pp. 937-49.

36. Y. Ru, S. Li, J. Zhou, Y. Pei, H. Wang, S. Gong, and H. Xu: Sci. Rep., 2016, https://doi.org/10.1038/srep29941.

37. R. Srinivasan, G.F. Eggeler, and M.J. Mills: Acta Mater., 2000, vol. 48, pp. 4867-78.

38. P.M. Sarosi, R. Srinivasan, G.F. Eggeler, M.V. Nathal, and M.J. Mills: Acta Mater., 2007, vol. 55, pp. 2509-18.

39. A. Kostka, G. Mälzer, G. Eggeler, A. Dlouhy, S. Reese, and T. Mack: J. Mater. Sci., 2007, vol. 42, pp. 3951-57.

40. A.I. Epishin and T. Link: Philos. Mag., 2004, vol. 84, pp. $1979-2000$. 
41. B. Viguier, F. Touratier, and E. Andrieu: Philos. Mag., 2011, vol. 91, pp. 4427-46.

42. A. Prakash and E. Bitzek: Materials, 2017, vol. 10, pp. 88-18.

43. T.P. Gabb, S.L. Draper, D.R. Hull, R.A. MacKay, and M.V. Nathal: Mater. Sci. Eng. A, 1989, vol. 118, pp. 59-69.

44. J.-B. le Graverend, L. Dirand, A. Jacques, J. Cormier, O. Ferry, T. Schenk, F. Gallerneau, S. Kruch, and J. Mendez: Metall. Mater. Trans. A, 2012, vol. 43A, pp. 3946-51.
45. I. Toda-Caraballo and P.E.J. Rivera-Díaz-del-Castillo: Acta Mater., 2015, vol. 85, pp. 14-23.

46. P Caron: Superalloys 2000 (Ninth International Symposium), 2000, pp. 737-46.

47. W.F. Gale and T.C. Totemeier: Smithells Metals Reference Book, Butterworth-Heinemann, Oxford, 2003.

48. E.I. Galindo-Nava, L.D. Connor, and C.M.F. Rae: Acta Materia., 2015, vol. 98, pp. 377-90. 